\title{
O DIREITO COMPARADO NA INTEGRAÇÃO DAS LACUNAS DE REGULAÇÃO
}

\section{COMPARATIVE LAW IN THE INTEGRATION OF REGULATION GAP}

\author{
MARCELO LAUAR LEITE*
}

\section{RESUMO}

À carência de normas que parametrizem certo fenômeno social se costuma associar o conceito de lacuna. Muito embora esta expressão evoque um significado usual - a falta de regulação -, ele não deve ser confundido com a existência de uma lacuna jurídica - ou falta de solução jurídica -, uma vez que o próprio ordenamento já oferece meios de integração para a ausência de normas específicas. Nas situações de carência abrangente, LARENZ entende haver lacunas de regulação. De certo, as lacunas de regulação são um problema que o positivismo, sozinho, não consegue resolver. Neste trabalho, sob as premissas epistemológicas popperianas, investigou-se o uso do Direito Comparado como ferramenta integrativa das lacunas de regulação. Verificou-se que o manejo do Direito Comparado tem larga aplicação não apenas como ferramenta integrativa das lacunas de regulação, mas também como meio dialógico a ser manejado de forma independente e/ou complementar.

PALAVRAS-CHAVE: Direito Comparado. Integração. Lacunas de regulação.

\begin{abstract}
The lack of norms that parameterize a certain social phenomenon is usually associated with the concept of gap. Although this expression evokes a usual meaning - the lack of regulation - it should not be confused with the existence of a legal gap - or lack of legal solution - since the order itself already offers means of integration for the absence of specific standards. In situations of comprehensive need, LARENZ understands that there are regulatory gaps. Of course, regulatory gaps are a problem that positivism alone cannot solve. In this paper, under the popperian methodological premises, we investigated the use of Comparative Law as an integrative tool for regulatory gaps. The management of Comparative Law has been widely applied not only as an integrative tool for regulatory gaps, but also as a dialogical means to be managed independently and / or complementarily.
\end{abstract}

KEYWORDS: Comparative Law. Integration. Regulatory gaps.

\section{O PROBLEMA E SUA COMPREENSÃO}

À carência de normas que parametrizem certo fenômeno social se costuma associar o conceito de lacuna. Muito embora esta expressão evoque um significado usual - a falta de regulação -, ele não deve ser confundido com a existência de uma lacuna jurídica - ou falta de solução jurídica -, uma vez que o próprio ordenamento já oferece meios de integração para a ausência de normas específicas.

* Doutor em Direito Empresarial pela Faculdade de Direito da Universidade de Coimbra (FDUC). Bacharel e Mestre em Direito pela Universidade Federal do Rio Grande do Norte (UFRN). Professor do Curso de Direito da Universidade Federal Rural do Semi-Árido, Mossoró - RN.E-mail: marcelolauar@yahoo.com.br. 
Nesses casos, não há falta de uma solução do ordenamento, mas, sim, a ausência de um fecho satisfatório; de regras que se desejariam existentes, mas que não existem ${ }^{1}$, revelando o que Bоввіо ${ }^{2}$ nominou de lacunas ideológicas (impróprias). O sistema, malgrado não seja completo, é completável pela sua própria força interna quando esta remete o aplicador aos meios de integração ${ }^{3}$.

Esclarecida a premissa pela qual se entende haver lacuna, parece claro que esta existe quando, para um dado caso particular, não é prevista alguma consequência jurídica por alguma regra pertencente ao sistema ${ }^{4}$. Assim, em geral, quando se fala que há lacuna para a solução de certo problema, quer-se dizer que falta uma solução legal específica, e não normativa.

Nas situações de carência abrangente, LARENZ ${ }^{5}$ entende haver lacunas de regulação. De certo, as lacunas de regulação são um problema que o positivismo, sozinho, não consegue resolver. Não por acaso, as próprias estruturas jurídicas postas remetem a fontes de integração. Talvez, por isso, CASTANHEIRA Neves seja tão incisivo no fato de o ordenamento positivo não ser o titular definidor da juridicidade, dado que as lacunas emergiriam por força de um devir histórico do jurídico que, continuamente, superaria o sistema positivo ${ }^{6}$. Com efeito, Direito e lei não se confundem, sendo impossível satisfazer as necessidades sociais somente com a manipulação exegética desta ${ }^{7}$. Nessa ordem, admitir um ordenamento sem lacunas seria levantar a esdrúxula hipótese de perenidade e/ou imutabilidade do Direito posto frente à dinâmica social, até chegar-se ao ponto no qual o Poder Legislativo, simplesmente, não teria mais o que desempenhar em sua função precípua, pois todas as condutas já estariam prescritas ${ }^{8}$.

Ainda assim, a lacuna de regulação não pode justificar a recusa de aplicação do direito ao caso concreto, isto é, a denegação de justiça, por imperativo legal derivado da LINDB e do CPC. Ante essa realidade, cabe aos magistrados a criação de normas de decisão, as quais, conquanto não substituam a vontade legislativa - apta a regular com efeitos erga omnes -, ao menos solucionam particularmente os casos levados à tutela jurisdicional do Estado?.

1 BOBBIO, 1996, p. 140; DIMOULIS, 2011, p. 160; LARENZ, 1997, p. 526.

2 BOBBIO, op. cit., p. 139-142.

3 DINIZ, 2000, p. 116. Para Воввіо (op. cit., p. 144), enquanto as lacunas próprias podem ser completadas pelo aplicador do Direito, as impróprias (ideológicas) só o poderiam ser pelo próprio legislador.

4 GUASTINI, 2005, p. 174.

5 LARENZ, op. cit., p. 528. Compartilhando essa definição, cf. BRONZE, 2006, p. 957.

6 CASTANHEIRA NEVES, 1993, p. 228-229.

7 CASTANHEIRA NEVES, 1995, p. 49; BRONZE, op. cit., p. 715 (Há mais direito para além do legislativamente prescrito).

8 DINIZ, op. cit., p. 109.

9 DINIZ, op. cit., p. 105. 
Neste trabalho ${ }^{10}$, sob as premissas epistemológicas popperianas ${ }^{11}$, pretende-se investigar o uso do Direito Comparado como ferramenta integrativa das lacunas de regulação. A questão tem importância ímpar, mormente em questões nas quais os meios tradicionais - analogia, costumes e princípios gerais de direi$t 0^{12}$, ou mesmo a forma como eles são manejados, não se adequam à necessidade integrativa. Se confirmada, a hipótese desse uso pode abrir novas janelas de suporte argumentativo na solução de questões jurídicas, ainda estas guardem cunho estritamente local.

Para atingir o fim almejado, foram descritos os mecanismos tradicionais de integração jurídica - analogia, costumes e princípios gerais do Direito -, cotejando suas insuficiências aplicativas. Em seguida, debruçou-se sobre a não exaustividade dos meios previstos no art $4^{\circ}$ da LINDB, resgatando-se as funções integrativas da equidade e do Direito Comparado enquanto ferramenta dialógica.

\section{PONDERAÇÕES SOBRE OS MECANISMOS DE INTEGRAÇÃO DO DIREITO}

$\mathrm{Na}$ busca de soluções para as lacunas de regulação, é certo que os limites legislativos necessitam ser integrados. Conquanto essa ação possa ser realizada academicamente, é inegável que seu campo prático se revela na seara jurisdicional ${ }^{13}$. Nas palavras de Esser, a jurisdição é o motor da atualização do Direito, cuja contínua atualização se objetiva em uma ordem jurídica translegal ${ }^{14}$. Se o legislador se mostra soberano no princípio, é a jurisprudência que, ao dizer a última palavra do direito, se revela soberana no fim ${ }^{15}$.

10 Publicação inédita em língua portuguesa, acatadas as sugestões dos pareceristas ad hoc em double blind review. Cf., em língua inglesa, com alterações, do mesmo autor: Comparative Law in the Integration of Regulatory Gaps, In: Scientia Ivridica, n. 357, Braga, 2021 [no prelo].

11 POPPER, Karl. Lógica das ciências sociais. Tradução de Estevão de Rezende Martins, Apio Cláudio Muniz Acquarone Filho e Vilma de Oliveira Moraes e Silva. Rio de Janeiro: Tempo Brasileiro, 2004.

12 Lei de Introdução às Normas do Direito Brasileiro (LINDB)

Art. $4^{\circ}$ Quando a lei for omissa, o juiz decidirá o caso de acordo com a analogia, os costumes e os princípios gerais de direito.

Cf., também nesse sentido, STRECK, 2014, p. 156 [(...) pode-se entender, sem dúvida, que, quando o juiz está autorizado/obrigado a julgar nos termos dos arts. $4^{\circ}$ da LINDB e 126 do CPC (isto é, deve sempre proferir uma decisão), isso significa que o ordenamento é, dinamicamente, completável, através de uma autorreferência ao próprio sistema jurídico].

13 A doutrina tem o condão de completar e antecipar a normatividade jurisdicional (CASTANHEIRA NEVES, 1995, p. 90).

14 Apud CASTANHEIRA NEVES, 1995, p. 82-84, para quem a ordem translegal seria a autêntica ordem jurídica objetiva; a que se pode dizer historicamente "em ação" e, por isso, verdadeiramente vigente. $\mathrm{O}$ direito jurisdicional seria, nesse sentido, o próprio processo de crescimento da lei, enquanto um indispensável complemento normativo na realização histórica de qualquer direito legal.

15 CASTANHEIRA NEVES, 1995, p. 83. 
Para adequar esse processo às expectativas sistêmicas, não incidindo em denegação de justiça, costuma-se utilizar meios de autointegração e heterointegração. No primeiro caso, tem-se o manejo da própria lei vigente para traçar métricas de superação à omissão-objeto; no segundo, recorre-se a outras fontes, sejam internas ou externas ${ }^{16}$. No Brasil, a LINDB prescreveu a analogia, os costumes e os princípios gerais de direito como meios de integração de lacunas. Permitiu, destarte, o emprego tanto de meios de autointegração - v.g., a analogia - quanto de heterointegração - v.g., os costumes.

\subsection{ANALOGIAS LEGIS E IURIS}

A primeira resposta legal visando à colmatação de lacunas de regulação é o manejo da analogia. Por esta, busca-se aplicar a uma hipótese não contida no direito positivo a solução ou resposta pertinente a um caso semelhante. Para tanto, embebe-se da ideia de sistema jurídico como um todo uno e harmôni$\mathrm{Co}^{17}$, procurando o tratamento isonômico entre fatos de igual natureza. Logo, pressupõe-se (i) uma hipótese não prevista; e (ii) a existência de um elemento de identidade essencial - ou decisivo - entre as relações paradigma (regulada) e paradigmática (que se pretende regular) ${ }^{18}$.

O elemento de identidade essencial para a aplicação da forma integrativa supra é a própria razão da lei. Emprega-se a analogia quando, na falta de conteúdo legal sobre certo tema, a situação que se pretende regular apresenta um motivo ou fundamento congênere àquela que já detém regulação, havendo, portanto, semelhança (correspondência) relevante e suficiente para que se atribua a uma o predicado da outra. Faz-se necessário, assim, atentar para a qualidade comum aos casos paradigma e paradigmático, que seja, ao mesmo tempo, a razão suficiente pela qual ao caso regulado foram atribuidas umas, e não outras consequências ${ }^{19}$.

16 BOBBIO, op. cit., p. 146-148; DINIZ, op. cit., p. 138-139.

17 DIMOULIS, op. cit., p. 161

18 MAXIMILIANO, 2010, p. 172-173; NADER, 2006, p. 194;

JUSTO, op. cit., p. 357; LARENZ, op. cit., p. 540-541. CASTANHEIRA NEVES (1993, p. 240) aponta que a correlação entre analogia e paradigma já era feita por MARCus Tullius CiCERo, em Timaeus.

19 BOBBIO, op. cit., p. 151-153; NADER, op. cit., p. 195; DINIZ, op. cit., p. 160; ASCENSÃO, op. cit., p. 922; JUSTO, op. cit., p. 356; BRONZE, op. cit., p. 940-941; ENGISCH, Karl. 2001, p. 290; VILANOVA, 1997, p. 250. Sobre o elemento de identidade essencial, parafraseia-se o didático exemplo de Norberto Bоввіо sobre uma lei que atribui uma multa a quem exerce o comércio de livros ensinando a fraudar a Fazenda Pública. Essa multa poderia se estender a quem comercializa livros policiais ou mídias digitais ensinando a fraudar a Fazenda Pública? No caso, é provável que o aplicador do direito, criador da norma de decisão, aceite a segunda possibilidade, recusando a primeira. Não se nega a semelhança entre livros impressos ensinando a fraudar a Fazenda Pública e os com histórias policiais: ambos são compostos por papel, tinta, etc. Ocorre que o que têm em comum - a estética do papel - não foi a razão suficiente $e$ essencial para a pena de multa estabelecida por lei. De outro lado, quanto às mídias digitais, contendo o material divulgador das artimanhas em face do Estado, há, sem dúvida, uma real 
A analogia como forma de superar lacunas está diretamente associada à função integradora e de pacificação do Direito. A hipótese paradigma, ao passar pelo processo legislativo, exterioriza os valores jurídicos dominantes para a situação regulada, moldando as expectativas e o comportamento social em certo sentido ${ }^{20}$. É esperado que, enquanto sistema de estabilização das relações humanas, o Direito confira soluções congêneres para casos com identidade essencial a outros por ele regulados, diminuindo o risco decisório e transformando a incerteza em expectativas razoáveis ${ }^{21}$, partindo do que é mais conhecido para aceder ao menos conhecido ${ }^{22}$.

A efetivação deste meio pode se dar tanto pela analogia legis (particular; em estrito senso) como pela iuris (geral; princípio geral do direito). Na primeira, parte-se de uma regra isolada e elimina-se os elementos não essenciais de uma regra paradigma, aplicando-a por identidade essencial ao caso paradigmático ${ }^{23}$. $\mathrm{Na}$ segunda, parte-se de um conjunto de normas jurídicas dos quais se deduz um principio geral ou ratio legis aplicável ao caso lacunoso ${ }^{24}$, construindo-se uma norma ínsita ao sistema pela combinação de muitas outras ${ }^{25}$.

Embora a aplicação da analogia como fonte de integração envolva um elemento lógico, este não é o único presente, de modo que a realização de um juízo de valor pelo intérprete figura-se inarredável. Sem a apreciação axiológica, não seria possivel constatações positivas ou negativas que levassem à certeza de que em certo caso paradigmático há a mesma razão que levou o legislador a disciplinar o caso paradigma ${ }^{26}$. Logo, a analogia guarda, simultaneamente, tanto uma investigação lógica, pela qual se busca o elemento de semelhança ou identidade essencial, quanto teleológica-axiológica, indagando-se os valores que informam a ordem jurídica nas relações paradigma e paradigmática ${ }^{27}$.

aproximação qualitativa, sendo a multa compatível ante a mesma razão de punir.

Castanheira Neves (1993, p. 241) também coloca a razão da lei [conclusão nivelada (ZIEHN) ou same-level-reasoning (RIVALDI)] como uma das características que devem estar presentes na aplicação da analogia. Soma, a estas, a subsistência da diferença entre as relações análogas e o fundamento específico de integração.

20 MARQUES, 2007, p. 85-91; JUSTO, op. cit., p. 357 [Como fundamento da analogia jurídica invoca-se o principio ubi eadem ratio, ibi eadem iuris dispositivo, que traduz uma ideia de justiça e de coerência normativa: a de disciplinar casos semelhantes de modo semelhante (...)].

21 J. M. BROEKMAN, apud CASTANHEIRA NEVES, 1993, p. 246.

22 BRONZE, op. cit., p. 938; 942-945.

23 A distinção entre os casos se restringiria a pontos secundários (JUSTO, op. cit., p. 358); ENGISCH, op. cit., p. 295.

24 JUSTO, op. cit., p. 358; ASCENSÃO, op. cit., p. 925-926; NADER, op. cit., p. 196; LARENZ, op. cit., p. 548; REALE, 2004, p. 298; VENOSA, 2006, p. 141.

25 DINIZ, op. cit., p. 163.

26 NADER, op. cit., p. 195; LARENZ, op. cit., p. 541; CASTANHEIRA NEVES, 1993, p. 249250 [(...) Não deve ser confundida a validade (ou correcção) lógica do raciocínio analógico com a sua indole puramente lógica].

27 DINIZ, op. cit., p. 147. Cf., nesse sentido, VILANOVA, op. cit., p. 251-252. [O suporte do argumento por analogia, no universo-do-Direito, é juízo-de-valor. (...). Quando estendemos o 
De fato, não basta que se encontrem uma, duas ou três semelhanças entre os casos se lhes falta a identidade essencial, ligando-os como uma ponte. Sob outro viés, deve-se justificar porque o que assemelha as hipóteses paradigma e paradigmática é mais forte e decisivo do que aquilo que as difere ${ }^{28}$. Como põe Maria Helena Diniz, havendo a correspondência, convém que ela seja dúplice, isto é, apropriada tanto à aplicação ao caso paradigmático quanto, ficcionalmente, ao paradigma, caso houvesse uma hipotética inversão de polos ${ }^{29}$.

Contudo, compartilhando do sentimento de SANTOS Justo ${ }^{30}$, não se pode considerar que a analogia é suscetível de dirimir toda a lacuna de regulação. Primeiro, porque, sendo a identidade da analogia tão-somente parcial, ela não produz uma certeza absoluta, mas mera probabilidade. Ademais, o caráter inacabado do ordenamento não permite que nele se encontrem todas as soluções, muito menos todas as situações potencialmente paradigmas.

A saída dada pelo jurista português encontra certo conforto ante o ordenamento lusitano, cujo Código Civil admite, em seu art. $10^{\circ}$, que, na falta de caso análogo, a situação concreta seja resolvida segundo a norma que o próprio intérprete criaria se houvesse de legislar dentro do espírito do sistema ${ }^{31}$. Parece difícil dissociar esse comando de uma remissão à analogia iuris, afinal, não se encontrando uma analogia estrita, far-se-ia um exercício de vidência normativa com base em princípios gerais de direito ${ }^{32}$. Não por acaso, OlIVEIRA AsCENSÃO 33 traduz o enunciado positivo nas seguintes palavras: na falta de caso análogo, o intérprete resolve a situação de harmonia com a norma que corresponda ao espirito do sistema.

Proceder como recomenda a analogia iuris - ou criação de norma ad $h o c^{34}$ - referida no diploma substantivo civil português permite uma pluralidade de proposições para cada lacuna encontrada, dado que o aplicador do direito agiria de modo muito próximo ao de um legislador instantâneo, diferindo

âmbito e incidência de uma norma jurídica, passando dos casos previstos para os casos não- previstos, fazemos a seleção valorativa da norma que vai exercer o papel de premissa maior. Depois, para construirmos a premissa menor, onde se afirma a semelhança, tomamos posição valorativa. (...)] e BOBBIO, op. cit., p. 136. [(...). Mas o ordenamento, em geral, nada nos diz sobre as condições com base nas quais dois casos podem ser considerados parecidos. A decisão sobre a semelhança dos casos cabe ao intérprete]

28 DIMOULIS, op. cit., p. 162; CASTANHEIRA NEVES, I993, p. 248.

29 DINIZ, op. cit., p. 142.

30 Op. cit., p. 354-355. Cf., ainda, DEL VECCHIO, 2003, p. 16-18. LARENz (op. cit., p. 571) chega a dizer que há lacunas não são susceptiveis de preenchimento.

31 ARTIGO $10^{\circ}$ (Integração das lacunas da lei)

$(\ldots)$

$\mathrm{Na}$ falta de caso análogo, a situação é resolvida segundo a norma que o próprio intérprete criaria, se houvesse de legislar dentro do espírito do sistema.

32 JUSTO, op. cit., p. 363.

33 Op. cit., p. 940.

34 JUSTO, op. cit., p. 361. 
deste somente por ter que conformar suas escolhas com os princípios gerais que norteiam o sistema e com os seus fundamentos de validade constitucional, enquanto os parlamentares são obrigados somente à obediência do segundo.

Enfim, sendo inviável a integração das lacunas de regulação por meio das analogias legis e iuris e na falta de previsão correlata à constante do diploma substantivo civil lusitano, pode se fazer necessário o uso dos costumes praeter legem.

\subsection{COSTUMES: PARA UMA RELAÇÃO COM A ATIVIDADE JU- RISDICIONAL}

O costume praeter legem, isto é, usado como fonte de integração do Direito, deriva de uma prática uniforme e reiterada de certo comportamento (elemento externo ou objetivo), sob a convicção de que sua obrigatoriedade corresponde a uma necessidade jurídica (elemento interno ou subjetivo) ${ }^{35}$. Sua formação advém, também, da jurisprudência ${ }^{36}$, que pode ser considerada como uma formadora de costumes jurídicos - algo próximo aos chamados direito judiciário (Воввіо) $)^{37}$ ou direito judicial (LARENZ) ${ }^{38}$.

Com efeito, nem todo produto da experiência jurisdicional pode ser considerado um costume jurídico. Em um juízo decisório, uma fundamentação racional origina uma solução concreta ao caso decidido, o qual passa a ser assimilável por outros juízos como exemplos reais de decisões para lides análogas. Assim, faz-se uma criação normativo-jurídica (material) sem participação direta da experiência legislativa (formal), a qual, embora mantenha sua natureza particular, permanece como alicerce para a inferência dos elementos que norteiam a aplicação do Direito ${ }^{39}$. Não se pode falar, nessa fase primariamente constitutiva, da existência de um costume, mas da aposição das bases para a eventual formação deste.

Em que pese o Brasil sempre ter se filiado ao civil law, há muito o sistema jurídico vem adotando os precedentes ${ }^{40}$ não apenas como auxiliares

35 DINIZ, op. cit., p. 197-198 [O uso (...) deverá ser uniforme e constante, isto é, que em idênticas situações sempre se aja da mesma maneira, sem qualquer interrupção, porque é impróprio das normas ter vigência temporária. A uniformidade e a constância do uso não se poderiam verificar sem um exercício por período razoavelmente longo (...)].

36 DINIZ, op. cit., p. 189-192.

37 Seria o método mais importante de heterointegração, calcado no poder criativo do juiz (op. cit., p. 149).

38 Op. cit., p. 610.

39 CASTANHEIRA NEVES, 1995, p. 31-33, para quem se deve admitir a existência de direito vigente que não tenha sido formalmente prescrito (p. 55-56).

40 Precedentes são resoluções em que a mesma questão jurídica, sobre a qual há que decidir novamente, já foi resolvida uma vez por um tribunal noutro caso. Vale como precedente não a resolução do caso concreto que adquiriu foça jurídica, mas só a resposta dada pelo tribunal, no quadro da fundamentação decisória, a uma questão jurídica que se põe da mesma maneira no caso a se resolver agora (LARENZ, op. cit., p. 611). 
interpretativos, mas, rigorosamente, como roteiros a ser obrigatoriamente seguidos pelos aplicadores do Direito - stare decisis. A possibilidade de uso dos precedentes atribui considerável autonomia aos tribunais na realização do Direto, o que deve ser compensado pelos magistrados com a contínua ponderação dos elementos de permanência dos critérios de formação das decisões-paradigma, bem como dos fatores que aproximem ou afastem esta da paradigmática $^{41}$.

O maior exemplo do uso dos precedentes no Brasil está, sem dúvida, no âmbito das súmulas vinculantes (CF, art. 103-A ${ }^{42}$ ). Efeitos similares são gerados pelas decisões proferidas pelo STF em controle concreto de constitucionalidade (CF, art. $\left.102, \mathbb{S} 2^{\circ 3}\right)$, as quais são de seguimento impositivo para os órgãos judiciários e à administração pública direta e indireta, seja nas esferas federal, estadual ou municipal. Quanto à legislação infraconstitucional, particularmente no Código de Processo Civil vigente a partir de 2016, os precedentes ganharam uma força considerável. Tendo os tribunais o dever de uniformizar a jurisprudência, mantendo-a estável, integra e coerente - art. 926 -, transferiuse aos magistrados a aparente obrigatoriedade de observância não apenas das súmulas vinculantes e das decisões proferidas em controle concentrado de constitucionalidade - diretamente derivadas da Constituição -, mas, também, (i) dos acórdãos proferidos em incidente de assunção de competência ou de resolução de demandas repetitivas e em julgamento de recursos extraordinário e especial repetitivos; (ii) dos enunciados das súmulas não vinculantes do Supremo Tribunal Federal em matéria constitucional, e do Superior Tribunal de Justiça em matéria infraconstitucional e (iii) da orientação do plenário ou do órgão especial aos quais estiverem vinculados - art. 927.

Especialmente com o novo CPC, a jurisprudência - considerada no seu sentido técnico, isto é, de precedentes reiterados - passou a ser utilizada pelos operadores do Direito como norma vigente. Esse fenômeno já ocorre em outros

41 CASTANHEIRA NEVES, 1995, p. 37.

42 Art. 103-A. O Supremo Tribunal Federal poderá, de ofício ou por provocação, mediante decisão de dois terços dos seus membros, após reiteradas decisões sobre matéria constitucional, aprovar súmula que, a partir de sua publicação na imprensa oficial, terá efeito vinculante em relação aos demais órgãos do Poder Judiciário e à administração pública direta e indireta, nas esferas federal, estadual e municipal, bem como proceder à sua revisão ou cancelamento, na forma estabelecida em lei.

(...).

43 Art. 102. Compete ao Supremo Tribunal Federal, precipuamente, a guarda da Constituição, cabendo-lhe:

(...)

$\mathbb{S} 2^{\circ}$ As decisões definitivas de mérito, proferidas pelo Supremo Tribunal Federal, nas ações diretas de inconstitucionalidade e nas ações declaratórias de constitucionalidade produzirão eficácia contra todos e efeito vinculante, relativamente aos demais órgãos do Poder Judiciário e à administração pública direta e indireta, nas esferas federal, estadual e municipal.

(...). 
países. Há muito, LARENZ ${ }^{44}$ aponta que, havendo grande probabilidade de os tribunais inferiores seguirem os superiores, e de que estes se atenham à sua própria jurisprudência, confia-se - naturalmente - no uso da jurisprudência como ferramenta de convencimento.

Assim, o teor jurisprudencial passa a ser visto como um autêntico costume jurídico, o qual passa a ser empregado, senão como fonte primária equivalente à lei, como modo de integração de lacunas. Alia-se, destarte, um elemento material - comportamento judicial repetido e constante - a um ideal - reconhecimento do caráter obrigatório desse comportamento ou da sua vinculação normativa -, formando precedentes aplicáveis a casos posteriores do mesmo tipo ${ }^{45}$.

\subsection{PRINCÍPIOS GERAIS DE DIREITO: PARA ALÉM DAANALOGIA IURIS}

A elaboração de soluções que se ajustem ao Direito vigente e que confiram alternativas ao legislador é um dos papéis da jurisprudência ${ }^{46}$. A analogia e os costumes, enquanto meios de integração, servem bem a essa função, porém, nem sempre são suficientes. De certo, há situações para as quais o legislador pode não ter previsto instrumentos com identidade essencial, tampouco cuja novidade não permitiu a criação de costumes, impedindo um prévio e consistente enfrentamento pelos tribunais. Para elas, a LINDB põe os princípios gerais de direito como terceira via de integração.

Tradicionalmente, tinha-se o Direito natural como integrador de lacunas do sistema positivo. Imaginava-se, para tanto, um ordenamento jurídico perfeito, o qual daria remédio às inevitáveis imperfeições legislativas. Gradualmente, o que se chamava de "Direito natural" foi substituído por uma expressão mais simples: "princípios gerais de direito" ${ }^{47}$. Nesse cenário, Воввіо ${ }^{48}$ relata que a maioria dos juristas interpretou a nova fórmula como "princípios gerais do direito positivo". Talvez, daí, tenha-se feito a associação entre princípios gerais de direito e a analogia iuris, de modo que o uso daqueles acarretaria, sempre, uma autointegração do sistema.

Em que pese a relação ínsita de ambos, eles não se confundem, sendo o primeiro, gênero; a segunda, espécie. A analogia iuris está contida nos princípios gerais de direito, mas estes não se exaurem naquela. Falar-se em princípios gerais "de" Direito não é o mesmo que falar-se em princípios gerais "do" Direito. Os

44 Op. cit., p. 611-612.

45 CASTANHEIRA NEVES, 1995, p. 20-22; DIMOULIS, op. cit., p. 185.

46 LARENZ, op. cit., p. 329-330.

47 BOBBIO, op. cit., p. 147. Sem renegar os autores que viam os princípios gerais de direito como os decorrentes da equidade (BORSARI), da natureza das coisas (GENY), da ciência e da filosofia do Direito (Beviláqua), entre outros (RÁO, 1952, p. 311).

48 Op. cit., p. 148. Igualmente, Del Vecchio afirma a quase unanimidade atual em se dissociar os princípios gerais de direito do Direito Natural (op. cit., p. 8-11). 
primeiros - previstos pela LINDB como meio integrador de lacunas - referemse ao Direito em geral. Os segundos, por sua vez, especificam - definem - um Direito específico, pelo que requerem um complemento - princípios gerais do Direito: de qual Direito?

Mostra-se contraditório entender que uma expressão tão ampla quanto "princípios gerais de Direito" signifique "princípios gerais do Direito... brasileiro", o que levaria a uma total interseção entre a primeira e a analogia iuris. Nas lições de Del VeCCHIO ${ }^{49}$, asseverar que os princípios gerais se referem a cada povo em particular - ou seja, que haja tantos princípios gerais quantos sistemas particulares - é uma contradição que guarda desarmonia com a própria letra da lei.

Em suma, os princípios expressos e implícitos do ordenamento vigente são princípios gerais de direito. Estes, sendo um gênero, albergam princípios de direito em geral, inclusive, se preciso for, os verificados no Direito Comparado ${ }^{50}$.

\section{DIREITO COMPARADO, EQUIDADE E DIALOGICIDADE.}

A busca de soluções integrativas no Direito Comparado - isto é, por heterointegração - é de inegável relevância prática e doutrinária ${ }^{51}$. No entanto, a importação de respostas estrangeiras aos problemas nacionais não se faz de maneira desorientada.

$\mathrm{Na}$ esteira dos ensinamentos de Fernando BronzE ${ }^{52}$, o Direito mundial pode ser agrupável em famílias, sendo possível falar-se em sistemas de inspiração cristã - em oposição a, v.g., ordens islâmicas -, democráticos de Direito - em oposição a ordens totalitárias -, e calcados no civil law-em oposição a ordens de origem no common law. Cada qual contém traços comuns, os quais, conquanto sejam importantes para fins comparatistas, não se bastam para afirmar haver uma homogeneidade tal que justifique a aplicação direta de hipóteses normativas alienígenas para as soluções de problemas locais.

49 Op. cit., p. 12. O autor, aliás, combate aquele sentido junto à expressão "princípios gerais do Direito"!

50 DINIZ, op. cit., p. 239; DANTAS, MALFATTI e CAMARGO, 2005, p. 66-67; FRANÇA, 1971, p. 218-223. Este autor teve o grande mérito de criar um roteiro metódico para a o manejo dos princípios gerais de Direito, o qual consiste em (i) só os admitir mediante falta de lei específica - como fonte integradora, tal qual dispõe a LINDB; (ii) os princípios aplicáveis seriam os que informam pré-ordenadamente o sistema jurídico positivo (contingentes) e aqueles não agasalhados intencionalmente pelo legislador (essenciais); (iii) os princípios contingentes preferem aos essenciais; (iv) os princípios devem ser aplicados em ordem cresce de generalização; $(v)$ os princípios contingentes do sistema jurídico positivo devem ser considerados antes dos do direito consuetudinário - logicamente, dado o manejo do costume como, também, uma fonte de integração - e, por fim, (v) o uso dos princípios contingentes do Direito Comparado. (Grifouse).

51 LARENZ, op. cit., p. 330; BOBBIO, op. cit., p. 148.

52 Op. cit., p. 699. Avançando nessa temática, DÁRIo ViCENTE pormenoriza e estabelece critérios para o enquadramento de cada uma dessas famílias jurídicas (VICENTE, 2012, p. 55-91). No Brasil, cf. SANTOS, 1962, p. 348-371. 
De fato, o desenvolvimento de cada sociedade engendra querelas de diferentes níveis econômico, social e cultural, as quais variam de acordo com elementos geográficos, políticos, culturais, entre outros. Mesmo quando os problemas são semelhantes, pode haver valoração distinta sobre eles ${ }^{53}$, de modo que o juiz deve estar convencido que as circunstâncias do caso criam uma base ideológica comum, possibilitando o albergue a um sistema jurídico estrangeiro como fonte de comparação e inspiração ${ }^{54}$. Trata-se de um trabalho cuidadoso, pois, em sociedades com esse nível de proximidade, os cidadãos estão menos propensos a aceitar que lides semelhantes produzam resultados diferentes ${ }^{55}$.

À interação ou cooperação entre instituições pertencentes a poderes estatais distintos para fins de resolução de conflitos, sem que haja a supremacia da atividade decisória de uma sobre outra, dá-se o nome de diálogos institucionais ${ }^{56}$. A missão dialógica do Direito Comparado, conquanto seja prática antiga, vem ganhando espaço na doutrina, a qual trata o fenômeno como o diálogo das jurisprudências (diálogo entre sistemas; diálogo delentre juizes; diálogo judicial; diplomacia judicial; transjudicialismo).

Esse diálogo não está - nem pode estar - restrito ao âmbito dos princípios gerais. Quando os métodos de integração previstos na LINDB falham, como justificar, juridicamente, decisões que contenham norteamentos extraídos em regras - e não princípios gerais - do Direito Comparado?

Nem mesmo o mais ferrenho crítico do diálogo entre sistemas deixaria de reconhecer o pragmatismo de se ter a viabilidade de adotar soluções estrangeiras ao caso concreto. Não se deve, por isso, conferir aos tribunais uma carta branca maquiavélica para chegar a decisões por quaisquer meios, principalmente em face do dever jurídico de fundamentação. Dizendo de outro modo, a eficácia do método para pôr fim a uma contenda não o justifica per si.

A saída para esse aparente dilema passa pela assunção do caráter não exaustivo dos meios integrativos previstos no art. $4^{\circ}$ da LINDB. Do contrário, haveria inexorável denegação de justiça em casos desamparados por elementos

53 VICENTE, op. cit., p. 18; MARKESINIS e FEDTKE, 2005, p. 59.

54 BARAK, 2005, p. 196.

55 MARKESINIS e FEDTKE, op. cit., p. 95.

56 DIAS JÚNIOR, 2012, p. 77. 
analógicos, consuetudinários ou da principiologia geral. Por essa razão, muitos autores $^{57}$ veem na equidade ${ }^{58}$ uma via implícita de integração de lacunas.

Desde Aristóteles, as definições sobre a equidade circundam em torno da justiça do caso concreto. Ainda hoje, a equidade se traduz na constante e permanente tentativa do julgador de conferir a melhor e mais justa decisão para o caso sob sua tutela ${ }^{59}$.

No Brasil, a equidade é a última ratio quando se trata de construção de normas casuísticas pelo magistrado. Estas, naturalmente, não devem ser sentimentais ou arbitrárias, mas fruto de uma elaboração científica, em harmonia com o espirito que rege o sistema e, especialmente, com os principios que informam o instituto objeto da decisão, estabelecendo-se uma norma individual para o caso omisso ${ }^{60}$. Tais balizas, aliás, são conferidas pelo art. $5^{\circ}$ da LINDB $^{61}$.

Nessa tarefa criadora imanente à experiência jurisdicional, mostra-se plenamente factível que o julgador, se baseando em regras pré-estabelecidas no Direito estrangeiro, as use como fonte de inspiração, adaptando-as ao sistema jurídico brasileiro.

Com efeito, a função heurística de colaborar com o desenvolvimento jurisprudencial é intrínseca à comparação entre sistemas jurídicos transnacionais. No Brasil, além do já expressamente autorizado pela Consolidação das Leis Trabalhistas $^{62}$, a experiência jurídica estrangeira vem, a cada dia, sendo perqui-

57 TARTUCE, 2010, p. 64; FRANÇA, 1988, p. 77; REALE, op. cit., p. 298; DINIZ, op. cit., p. 264; VENOSA, op. cit., p. 147.

Não se pode desconsiderar a existência de alguma objeção ao uso da equidade como uma quarta via de integração, dado o disposto no art. 140, parágrafo único, do CPC ("O juiz só decidirá por equidade nos casos previstos em lei"). Contra ela, diga-se que essa regra simplesmente pretende evitar que o legislador venha a se transformar em legislador casuístico, afastando o direito objetivo ou os meios de integração previstos na LINDB para, arbitrariamente, decidir de maneira equitativa. Nesse sentido, já se pronunciou o STJ (REsp n. ${ }^{\circ} 48176$, publicado em 8-4-1996), in verbis:

"EQUIDADE - ARTIGO 127 DO C.P.C. A PROIBIÇÃO DE QUE O JUIZ DECIDA POR EQUIDADE, SALVO QUANDO AUTORIZADO POR LEI, SIGNIFICA QUE NÃO HAVERA DE SUBSTITUIR A APLICAÇÃO DO DIREITO OBJETIVO POR SEUS CRITERIOS PESSOAIS DE JUSTIÇA. NÃO HA DE SER ENTENDIDA, ENTRETANTO, COMO VEDANDO SE BUSQUE ALCANÇAR A JUSTIÇA NO CASO CONCRETO, COM ATENÇÃO AO DISPOSTO NO ARTIGO $5^{\circ}$ DA LEI DE INTRODUÇÃO. CLAUSULA PENAL - ARTIGO 927 DP CÓDIGO CIVIL. (...)”.

Em Portugal, em face da já mencionada elaboração de normas ad hoc pelo Código Civil, foi superada a consideração da equidade como meio de integração - Cf. JUSTO, op. cit., p. 366.

58 Tratando, então, da chamada equidade judicial, isto é, aquela que, expressa ou implicitamente, o legislador incumbe o magistrado de levar a efeito. (FRANÇA, Hermenêutica jurídica, op. cit., p. 73).

59 VENOSA, op. cit., p. 146.

60 FRANÇA, Hermenêutica jurídica, op. cit., p. 50-51; 77 - O que impede, obviamente, uma decisão contrária à lei vigente - DINIZ, op. cit., p. 265.

61 Art. $5^{\circ} \mathrm{Na}$ aplicação da lei, o juiz atenderá aos fins sociais a que ela se dirige e às exigências do bem comum.

62 Art. $8^{\circ}$ - As autoridades administrativas e a Justiça do Trabalho, na falta de disposições legais ou contratuais, decidirão, conforme o caso, pela jurisprudência, por analogia, por eqüidade e 
rida para o encontro de respostas aos novos dilemas levados aos tribunais - semelhante ao que também ocorre em Portugal e outros países ${ }^{63}$.

Na medida em que o exame de uma solução estrangeira pode ajudar juízes nacionais a encontrarem saídas adequadas às lides aqui tuteladas ${ }^{64}$, a comparação entre sistemas jurídicos distintos vem se mostrando como uma ferramenta equitativa de notória importância. Exemplo historicamente recente disso foi a postura do STF quando da regulação do direito de greve dos servidores públicos civis. Com base no Direito Comparado - experiências alemã e italiana -, a Corte Suprema brasileira admitiu que fossem tomadas medidas normativas como alternativa legítima de superação de omissões inconstitucionais ${ }^{65}$. Integrou-se, assim, toda uma lacuna de regulação existente sobre o tema.

outros princípios e normas gerais de direito, principalmente do direito do trabalho, e, ainda, de acordo com os usos e costumes, o direito comparado, mas sempre de maneira que nenhum interesse de classe ou particular prevaleça sobre o interesse público. (Grifou-se).

63 VICENTE, op. cit., p. 21-22; NEVES, 2009, p. 168. Para acesso a trabalho jurimétrico acerca do manejo desse expediente, $c f$. GROPPI e PONTHOREAU, 2013.

64 MARKESINIS e FEDTKE, op. cit., p. 69; ROTHENBURG, 2014, p. 43; BARAK, op. cit., p. 196 [(...) Comparative law awakens judges to the potential latent in their own legal systems. It informs judges about the successes and failures that may result from adopting a particular legal solution. It refers judges to the relationship between a solution to the legal problem before them and other legal problems. Thus, comparative law acts as an experienced friend].

65 STF, MI n. ${ }^{\circ}$ 708, publicado em 31-10-2008. No mesmo sentido, $c f$. MI n. ${ }^{\circ}$ 670/ES, publicado em 31-10-2008, ambos com a mesma ementa, in verbis:

"MANDADO DE INJUNÇÃO. GARANTIA FUNDAMENTAL (CF, ART. 5”, INCISO LXXI). DIREITO DE GREVE DOS SERVIDORES PÚBLICOS CIVIS (CF, ART. 37, INCISO VII). EVOLUÇÃO DO TEMA NA JURISPRUDENCIA DO SUPREMO TRIBUNAL FEDERAL (STF). DEFINIÇÃO DOS PARÂMETROS DE COMPETÊNCIA CONSTITUCIONAL PARA APRECIAÇÃO NO ÂMBITO DA JUSTIÇA FEDERAL E DA JUSTIÇA ESTADUAL ATÉ A EDIÇÃO DA LEGISLAÇÃO ESPECÍFICA PERTINENTE, NOS TERMOS DO ART. 37, VII, DA CF. EM OBSERVÂNCIA AOS DITAMES DA SEGURANCA JURÍDICA E À EVOLUÇÃO JURISPRUDENCIAL NA INTERPRETAÇÃO DA OMISSĂOO LEGISLATIVA SOBRE O DIREITO DE GREVE DOS SERVIDORES PÚBLICOS CIVIS, FIXAÇÃO DO PRAZO DE 60 (SESSENTA) DIAS PARA QUE O CONGRESSO NACIONAL LEGISLE SOBRE A MATÉRIA. MANDADO DE INJUNÇÃO DEFERIDO PARA DETERMINAR A APLICAÇÃO DAS LEIS N ${ }^{\circ}$ 7.701/1988 E 7.783/1989. 1. SINAIS DE EVOLUÇÃO DA GARANTIA FUNDAMENTAL DO MANDADO DE INJUNÇÃO NA JURISPRUDÊNCIA DO SUPREMO TRIBUNAL FEDERAL (STF). 1.1. No julgamento do MI $n^{\circ}$ 107/DF, Rel. Min. Moreira Alves, DJ 21.9.1990, o Plenário do STF consolidou entendimento que conferiu ao mandado de injunção os seguintes elementos operacionais: i) os direitos constitucionalmente garantidos por meio de mandado de injunção apresentam-se como direitos à expedição de um ato normativo, os quais, via de regra, não poderiam ser diretamente satisfeitos por meio de provimento jurisdicional do STF; ii) a decisão judicial que declara a existência de uma omissão inconstitucional constata, igualmente, a mora do órgão ou poder legiferante, insta-o a editar a norma requerida; iii) a omissão inconstitucional tanto pode referir-se a uma omissão total do legislador quanto a uma omissão parcial; iv) a decisão proferida em sede do controle abstrato de normas acerca da existência, ou não, de omissão é dotada de eficácia erga omnes, e não apresenta diferença significativa em relação a atos decisórios proferidos no contexto de mandado de injunção; iv) o STF possui competência constitucional para, na ação de mandado de injunção, determinar a suspensão de processos administrativos ou judiciais, com o intuito de assegurar ao interessado a possibilidade de ser contemplado por norma mais benéfica, ou que lhe assegure o direito constitucional invocado; $v$ ) por fim, esse plexo de poderes institucionais legitima que o STF determine a edição de outras medidas que garantam a posição do impetrante até a oportuna expedição de normas pelo legislador. 1.2. Apesar 


\section{Uma das características do mundo contemporâneo é a busca de respostas}

dos avanços proporcionados por essa construção jurisprudencial inicial, o STF flexibilizou a interpretação constitucional primeiramente fixada para conferir uma compreensão mais abrangente à garantia fundamental do mandado de injunção. A partir de uma série de precedentes, o Tribunal passou a admitir soluções "normativas" para a decisão judicial como alternativa legítima de tornar a proteção judicial efetiva (...) 2. O MANDADO DE INJUNÇÃO E O DIREITO DE GREVE DOS SERVIDORES PÚBLICOS CIVIS NA JURISPRUDÊNCIA DO STF. 2.1. O tema da existência, ou não, de omissão legislativa quanto à definição das possibilidades, condições e limites para o exercício do direito de greve por servidores públicos civis já foi, por diversas vezes, apreciado pelo STF. Em todas as oportunidades, esta Corte firmou o entendimento de que o objeto do mandado de injunção cingir-se-ia à declaração da existência, ou não, de mora legislativa para a edição de norma regulamentadora específica. Precedentes. (...) 2.2. Em alguns precedentes (...), aventou-se a possibilidade de aplicação aos servidores públicos civis da lei que disciplina os movimentos grevistas no âmbito do setor privado (Lei no 7.783/1989). 3. DIREITO DE GREVE DOS SERVIDORES PÚBLICOS CIVIS. HIPÓTESE DE OMISSÃO LEGISLATIVA INCONSTITUCIONAL. MORA JUDICIAL, POR DIVERSAS VEZES, DECLARADA PELO PLENÁRIO DO STF. RISCOS DE CONSOLIDAÇÃO DE TÍPICA OMISSÃO JUDICIAL QUANTO À MATÉRIA. A EXPERIÊNCIA DO DIREITO COMPARADO. LEGITIMIDADE DE ADOÇÃO DE ALTERNATIVAS NORMATIVAS E INSTITUCIONAIS DE SUPERAÇÃO DA SITUAÇÃO DE OMISSÃO. 3.1. A permanência da situação de não-regulamentação do direito de greve dos servidores públicos civis contribui para a ampliação da regularidade das instituições de um Estado democrático de Direito $\left(\mathrm{CF}\right.$, art. $\left.1^{\circ}\right)$. Além de o tema envolver uma série de questões estratégicas e orçamentárias diretamente relacionadas aos serviços públicos, a ausência de parâmetros jurídicos de controle dos abusos cometidos na deflagração desse tipo específico de movimento grevista tem favorecido que o legítimo exercício de direitos constitucionais seja afastado por uma verdadeira "lei da selva”. 3.2. Apesar das modificações implementadas pela Emenda Constitucional no 19/1998 quanto à modificação da reserva legal de lei complementar para a de lei ordinária específica (CF, art. 37, VII), observa-se que o direito de greve dos servidores públicos civis continua sem receber tratamento legislativo minimamente satisfatório para garantir o exercício dessa prerrogativa em consonância com imperativos constitucionais. 3.3. Tendo em vista as imperiosas balizas jurídico-políticas que demandam a concretização do direito de greve a todos os trabalhadores, o STF não pode se abster de reconhecer que, assim como o controle judicial deve incidir sobre a atividade do legislador, é possivel que a Corte Constitucional atue também nos casos de inatividade ou omissão do Legislativo. 3.4. A mora legislativa em questão já foi, por diversas vezes, declarada na ordem constitucional brasileira. Por esse motivo, a permanência dessa situação de ausência de regulamentação do direito de greve dos servidores públicos civis passa a invocar, para si, os riscos de consolidação de uma típica omissão judicial. 3.5. Na experiência do direito comparado (em especial, na Alemanha e na Itália), admite-se que o Poder Judiciário adote medidas normativas como alternativa legítima de superação de omissões inconstitucionais, sem que a proteção judicial efetiva a direitos fundamentais se configure como ofensa ao modelo de separação de poderes (CF, art. $2^{\circ}$ ). 4. DIREITO DE GREVE DOS SERVIDORES PÚBLICOS CIVIS. REGULAMENTACÃO DA LEI DE GREVE DOS TRABALHADORES EM GERAL (LEI N ${ }^{\circ}$ 7.783/1989). FIXAÇÃO DE PARÂMETROS DE CONTROLE JUDICIAL DO EXERCÍCIO DO DIREITO DE GREVE PELO LEGISLADOR INFRACONSTITUCIONAL. 4.1. A disciplina do direito de greve para os trabalhadores em geral, quanto às "atividades essenciais", é especificamente delineada nos arts. $9^{\circ}$ a 11 da Lei no 7.783/1989. Na hipótese de aplicação dessa legislação geral ao caso específico do direito de greve dos servidores públicos, antes de tudo, afigura-se inegável o conflito existente entre as necessidades mínimas de legislação para o exercício do direito de greve dos servidores públicos civis (CF, art. $9^{\circ}$, caput, clc art. 37, VII), de um lado, e o direito a serviços públicos adequados e prestados de forma contínua a todos os cidadãos $\left(\mathrm{CF}\right.$, art. $\left.9^{\circ}, \mathbb{S} 1^{\circ}\right)$, de outro. Evidentemente, não se outorgaria ao legislador qualquer poder discricionário quanto à edição, ou não, da lei disciplinadora do direito de greve. O legislador poderia adotar um modelo mais ou menos rígido, mais ou menos restritivo do direito de greve no âmbito do serviço público, mas não poderia deixar de reconhecer direito previamente definido pelo texto da Constituição. Considerada a evolução jurisprudencial do tema perante o STF, em sede do mandado de injunção, não se pode atribuir amplamente ao legislador a última palavra acerca da concessão, ou não, do direito de greve dos servidores públicos civis, sob pena de se esvaziar direito fundamental positivado. Tal premissa, contudo, não impede que, futuramente, o legislador infraconstitucional con- 
jurídicas e sua consequente difusão, de modo que, para (quase) toda singularidade casuística, não se está sozinho: alguém, em algum lugar, (muito provavelmente) a enfrentou ${ }^{66}$. Com efeito, antes de um magistrado se posicionar sobre certa

fira novos contornos acerca da adequada configuração da disciplina desse direito constitucional. 4.2 Considerada a omissão legislativa alegada na espécie, seria o caso de se acolher a pretensão, tão-somente no sentido de que se aplique a Lei $n^{\circ} 7.783 / 1989$ enquanto a omissão não for devidamente regulamentada por lei especifica para os servidores públicos civis (...) 6 . DEFINIÇÃO DOS PARÂMETROS DE COMPETENCIA CONSTITUCIONAL PARA APRECIAÇÃO DO TEMA NO ÂMBITO DA JUSTIÇA FEDERAL E DA JUSTIÇA ESTADUAL ATÉ A EDIÇÃO DA LEGISLAÇÃO ESPECÍFICA PERTINENTE, NOS TERMOS DO ART. 37, VII, DA CF. FIXAÇÃO DO PRAZO DE 60 (SESSENTA) DIAS PARA QUE O CONGRESSO NACIONAL LEGISLE SOBRE A MATÉRIA. MANDADO DE INJUNÇÃO DEFERIDO PARA DETERMINAR A APLICAÇÃO DAS LEIS Nº 7.701/1988 E 7.783/1989. 6.1. Aplicabilidade aos servidores públicos civis da Lei $n^{\circ} 7.783 / 1989$, sem prejuizo de que, diante do caso concreto e mediante solicitação de entidade ou órgão legítimo, seja facultado ao juízo competente a fixação de regime de greve mais severo, em razão de tratarem de "serviços ou atividades essenciais" (Lei $n^{\circ} 7.783 / 1989$, arts. $9^{\circ}$ a 11). 6.2. Nessa extensão do deferimento do mandado de injunção, aplicação da Lei $n^{\circ} 7.701 / 1988$, no que tange à competência para apreciar e julgar eventuais conflitos judiciais referentes à greve de servidores públicos que sejam suscitados até o momento de colmatação legislativa específica da lacuna ora declarada, nos termos do inciso VII do art. 37 da CF. 6.3. Até a devida disciplina legislativa, devem-se definir as situações provisórias de competência constitucional para a apreciação desses dissídios no contexto nacional, regional, estadual e municipal. Assim, nas condições acima especificadas, se a paralisação for de âmbito nacional, ou abranger mais de uma região da justiça federal, ou ainda, compreender mais de uma unidade da federação, a competência para o dissídio de greve será do Superior Tribunal de Justiça (por aplicação analógica do art. 20, I, "a”, da Lei $n^{\circ}$ 7.701/1988). Ainda no âmbito federal, se a controvérsia estiver adstrita a uma única região da justiça federal, a competência será dos Tribunais Regionais Federais (aplicação analógica do art. $6^{\circ}$ da Lei $n^{\circ}$ 7.701/1988). Para o caso da jurisdição no contexto estadual ou municipal, se a controvérsia estiver adstrita a uma unidade da federação, a competência será do respectivo Tribunal de Justiça (também por aplicação analógica do art. $6^{\circ}$ da Lei no 7.701/1988). As greves de âmbito local ou municipal serão dirimidas pelo Tribunal de Justiça ou Tribunal Regional Federal com jurisdição sobre o local da paralisação, conforme se trate de greve de servidores municipais, estaduais ou federais. 6.4. Considerados os parâmetros acima delineados, a par da competência para o dissídio de greve em si, no qual se discuta a abusividade, ou não, da greve, os referidos tribunais, nos âmbitos de sua jurisdição, serão competentes para decidir acerca do mérito do pagamento, ou não, dos dias de paralisação em consonância com a excepcionalidade de que esse juízo se reveste. Nesse contexto, nos termos do art. $7^{\circ}$ da Lei $n^{\circ}$ 7.783/1989, a deflagração da greve, em princípio, corresponde à suspensão do contrato de trabalho. Como regra geral, portanto, os salários dos dias de paralisação não deverão ser pagos, salvo no caso em que a greve tenha sido provocada justamente por atraso no pagamento aos servidores públicos civis, ou por outras situações excepcionais que justifiquem o afastamento da premissa da suspensão do contrato de trabalho (art. $7^{\circ}$ da Lei $n^{\circ} 7.783 / 1989$, in fine). 6.5. Os tribunais mencionados também serão competentes para apreciar e julgar medidas cautelares eventualmente incidentes relacionadas ao exercício do direito de greve dos servidores públicos civis, tais como: i) aquelas nas quais se postule a preservação do objeto da querela judicial, qual seja, o percentual mínimo de servidores públicos que deve continuar trabalhando durante o movimento paredista, ou mesmo a proibição de qualquer tipo de paralisação; ii) os interditos possessórios para a desocupação de dependências dos órgãos públicos eventualmente tomados por grevistas; e iii) as demais medidas cautelares que apresentem conexão direta com o dissídio coletivo de greve. 6.6. Em razão da evolução jurisprudencial sobre o tema da interpretação da omissão legislativa do direito de greve dos servidores públicos civis e em respeito aos ditames de segurança jurídica, fixa-se o prazo de 60 (sessenta) dias para que o Congresso Nacional legisle sobre a matéria. 6.7. Mandado de injunção conhecido e, no mérito, deferido para, nos termos acima especificados, determinar a aplicação das Leis $n^{\circ}$ 7.701/1988 e 7.783/1989 aos conflitos e às ações judiciais que envolvam a interpretação do direito de greve dos servidores públicos civis”." (Grifou-se).

66 DANTAS, 1997, p. 244; KOOPMANS, 1996, p. 550; BARAK, 2006, p. 197-202. 
questão, seria prudente, independentemente do cotejo equitativo, avaliar como outros sistemas jurídicos a tratam. Assumindo essa postura, contribuir-se-ia, de qualquer forma, para o enriquecimento dos sistemas legais de origem comum ${ }^{67}$.

Allard e EYNDE ${ }^{68}$ sistematizaram razões de ordem pragmática, racionalista e política para justificar o diálogo entre sistemas, às quais se adere integralmente. Pragmaticamente, o direito estrangeiro é uma "caixa de ferramentas" para resolver problemas reais e complexos ${ }^{69}$, sendo um grande facilitador para juízos de equidade integrativa. Na ótica racionalista, a ampliação dos horizontes dos operadores do Direito (i) permite a reflexão sobre as bases do sistema nacional ${ }^{70}$, (ii) melhora os argumentos, (iii) aumenta a autoridade persuasiva e (iii) a legitimidade das decisões ${ }^{71}$. Por fim, quanto ao aspecto político, o diálogo viabiliza (i) a harmonização de normas jurídicas em torno de um núcleo de valores comuns $\mathrm{s}^{72} \mathrm{e}$ (ii) o desenvolvimento da influência e da independência internacional de cada jurisdição ${ }^{73}$.

Inseridas nesse cenário de intercâmbio de desfechos, as pertinências familiares supracitadas figuram como apenas um dos aspectos do dinâmico processo de comparação entre sistemas jurídicos distintos. Além delas, MARKESINIs e FEDTKE ${ }^{74}$ chegaram a conclusões adicionais ao se perguntarem quando o diálogo de sistemas poderia ocorrer: havendo (i) lacuna, ambiguidade ou óbvia necessidade de modernização do direito pátrio; (ii) desejo de se dar uma solução harmônica a problemas que, geograficamente, ultrapassem as fronteiras do país; (iii) evidência que a solução estrangeira funcionou empiricamente; (iv) origem da lei estrangeira em norma internacional e $(v)$ necessidade de solução de questões altamente especializadas do ponto de vista técnico, ao invés de questões axiológicas ${ }^{75}$.

67 BARAK, op. cit., p. 197.

68 ALLARD e EYNDE, 2013, p. 299-300.

69 No mesmo sentido, cf. ROTHENBURG, op. cit., p. 45.

70 O que vai ao encontro da categorização da comparação jurídica como método interpretativo (HÂBERLE e KOTZUR, 2003, p. 14); NEVES, op. cit., p. 183.

71 Trata-se, nesse ponto, de uma prática de argumentação comparativa (comparative reasoning). Aqui, assume-se simultaneamente características de um argumento de autoridade - pois se utiliza de uma proposição construída/definida por instituições legislativas/judiciárias estrangeiras as quais se atribui uma expertise ou prestígio para convencer/persuadir os seus destinatários - e analógico - pois toma como referência as soluções encontradas no contexto de outros ordenamentos para casos que são considerados semelhantes ao objeto de julgamento (VALE, 2014); NEVES, op. cit., p. 119.

72 No mesmo sentido, cf. OVÍDIO, 1984, p. 166; SANTOS, op. cit., p. 349. Este autor considera o Direito Comparado também como uma arte, pela qual, apoiando-se sobre os dados da experiência e observação, propõe-se a utilizar os pontos comuns extraídos das diversas instituições estrangeiras para reduzir as diferenças que subsistem entre as legislações positivas (op. cit., p. $353)$.

73 No mesmo sentido, cf. OVÍDIO, op. cit., p. 166-167.

74 Op. cit., p. 90-109.

75 É particularmente em casos difíceis que se recorrem a soluções estrangeiras (ALLARD e EYN- 


\section{CONSIDERAÇÕES FINAIS}

Pelo exposto até aqui, resta claro que o manejo do Direito Comparado tem larga aplicação não apenas como ferramenta integrativa das lacunas de regulação, mas também como meio dialógico a ser manejado de forma independente e/ou complementar.

Enquanto ferramenta integrativa, viu-se que nos princípios gerais de direito, mecanismos de integração expressamente previstos pela LINDB, estão inseridos os aferidos no Direito Comparado, de acordo com critérios de pertinência familiar e de base ideológica comum entre os sistemas sob cooperação.

Adicionalmente, mostrou-se que não é necessário o recurso à equidade como último estágio de superação de lacunas para se amparar em soluções estrangeiras. Independente do fenômeno das lacunas, a aplicação do Direito Comparado nas outras hipóteses supracitadas é utilizada por operadores do Direito em geral visando a aprimorar a regulação dos fatos sociais ${ }^{76}$, encontrar solução para problemas jurídicos (antecedente) ou justificar soluções já tomadas (consequente) ${ }^{77}$ como suporte argumentativo adicional durante a aplicação das próprias regras e princípios do sistema jurídico posto. Em outras palavras, aliam-se Direitos vigente e estrangeiro para solucionar questões de natureza similar.

A relevância teórica e prática do assunto é palpável e espera-se, nestas linhas, ter-se contribuído com a evolução do estado da arte.

\section{REFERÊNCIAS}

ALLARD, Julie; EYNDE, Laura Van den. Le dialogue des jurisprudences comme source du droit: arguments entre idéalisation et scepticisme. In: HACHEZ, Isabelle et al (org.). Les sources du Droit revisitées. v. 3. Limal: Anthemis, 2013.

BARAK, Aharon. Response to The Judge as Comparatist: comparison in Public Law. Tulane Law Review, New Orleans, v. 80, p. 195-202, 2005.

BARAK, Aharon. The judge in a democracy. New Jersey: Princeton University Press, 2006, p. 197-202.

BOBBIO, Norberto. Teoria do ordenamento jurídico (Tradução de Maria Celeste Cordeiro Leite dos Santos). 6. ed. Brasília: Edunb, 1996.

BRONZE, José Fernando. Lições de introdução ao Direito. 2. ed. Coimbra: Coimbra Editora, 2006.

DE, op. cit., p. 312).

76 DANTAS, op. cit., p. 244.

77 KOOPMANS, op. cit., p. 556. 
CASTANHEIRA NEVES, A. Metodologia jurídica: problemas fundamentais. Coimbra: Coimbra Editora: 1993.

- Digesta: escritos acerca do Direito, do pensamento jurídico, da sua metodologia e outros. v. 2. Coimbra: Coimbra Editora, 1995.

DANTAS, Ivo. Direito Comparado como ciência. Revista de Informação Legislativa, Brasília, v. 34, n. 134, p. 231-250, abri-jun 1997.

DANTAS, Aldemiro; MALFATTI, Alexandre D.; CAMARGO, Elizeu A. Lacunas do ordenamento jurídico. Barueri: Manole, 2005.

DEL VECCHIO, Giorgio. Princípios gerais do Direito. Tradução de Fernando de Bragança. Belo Horizonte: Lider, 2003.

DIAS JÚNIOR, Etéocles Brito Mendonça. Soberania parlamentar,judicial review e diálogosinstitucionais: do isolamento decisionista à atividade colaborativa entreos poderes na aplicação constitucional (Dissertação de Mestrado). Rio de Janeiro: Pontifícia Universidade Católica, 2012.

DIMOULIS, Dimitri. Manual de introdução ao estudo do Direito. 4. ed. São Paulo: Revista dos Tribunais, 2011.

DINIZ, Maria Helena. As lacunas no Direito. 6. ed. São Paulo: Saraiva, 2000.

ENGISCH, Karl. Introdução ao pensamento jurídico. Lisboa: Fundação Calouste Gulbenkian, 2001.

FRANÇA, R. Limongi. Hermenêutica jurídica. 2. ed. São Paulo: Saraiva, 1988. . Princípios gerais de Direito. 2. ed. São Paulo: Revista dos Tribunais, 1971.

GUASTINI, Riccardo. Das fontes às normas. Traduzido por Edson Bini. São Paulo: Quartier Latin, 2005.

GROPPI, Tania; PONTHOREAU, Marie-Claire. The use of foreign precedents by constitutional judges. Oxford: Hart Publishing, 2013.

HÄBERLE, Peter; KOTZUR, Markus. De la soberania al derecho constitucional común: palabras clave para un diálogo europeo-latinoamericano. Tradução de Héctor Fix-Fierro. Cidade do México: Universidad Nacional Autónoma de México, 2003.

KOOPMANS, T. Comparative Law and the courts. International and Comparative Law Quarterly, Cambridge, v. 45, n. 3, p. 545-556, jul-1996.

KOTZUR, Markus. De la soberania al derecho constitucional común: palabras clave para un diálogo europeo-latinoamericano. Tradução de Héctor Fix-Fierro. Cidade do México: Universidad Nacional Autónoma de México, 2003. 
LARENZ, Karl. Metodologia da ciência do direito. 3. ed. Lisboa: Fundação Calouste Gulbenkian, 1997.

MARKESINIS, Sir Basil; FEDTKE, Jorg. The Judge as Comparatist. Tulane Law Review, New Orleans, v. 80, p. 12-167, 2005.

MARQUES, Mário Reis. Introdução ao Direito. v. 1. 2. ed. Coimbra: Almedina, 2007.

MAXIMILIANO, Carlos. Hermenêutica e aplicação do Direito. 19. ed. Rio de Janeiro: Forense, 2010.

NADER, Paulo. Introdução ao estudo do Direito. 26. ed. Rio de Janeiro: Forense, 2006.

NEVES, Marcelo. Transconstitucionalismo. São Paulo: Martins Fontes, 2009.

OVÍDIO, Francisco. Aspectos do Direito Comparado. Revista da Faculdade de Direito, Universidade de São Paulo, v. 79, p. 161-180, jan. 1984.

POPPER, Karl. Lógica das ciências sociais. Tradução de Estevão de Rezende Martins, Apio Cláudio Muniz Acquarone Filho e Vilma de Oliveira Moraes e Silva. Rio de Janeiro: Tempo Brasileiro, 2004.

RÁO, Vicente. O Direito e a vida dos Direitos. v. 1. São Paulo: Max Limonad, 1952.

REALE, Miguel. Lições preliminares de Direito. 27. ed. São Paulo: Saraiva, 2004.

ROTHENBURG, Walter Claudius. Diálogo internacional entre juízes: a influência do direito estrangeiro e do direito internacional na solução de casos de direitos fundamentais. In: MARINHO, Maria Edelvacy et. al. (org.). Diálogos entre juízes. Brasília: UniCEUB, 2014.

SANTOS, José Nicolau dos. Direito Comparado e Geografia Jurídica. Estudos Jurídicos em honra de Soriano de Souza, v. 2, Recife, p. 348-371, 1962.

STRECK, Lenio Luiz. Hermenêutica jurídica e(m) crise: uma exploração hermenêutica da construção do Direito. 11. ed. Porto Alegre: Livraria do Advogado, 2014.

TARTUCE, Flávio. Direito civil: lei de introdução e parte geral. 6. ed. v. 1. São Paulo: Método, 2010.

VALE, André Rufino do. O argumento comparativo na jurisdição constitucional. In: Consultor Jurídico, São Paulo, mai-2014, disponível em: http://www. conjur.com.br/2014-mai-03/observatorio-constitucional-argumento-comparativo-jurisdicao-constitucional. Acesso em 23-8-2019. 
VENOSA, Sílvio de Salvo. Introdução ao estudo do Direito. 2. ed. São Paulo: Atlas, 2006.

VICENTE, Dário Moura. Direito comparado. v. 1. 2. ed. Coimbra: Almedina, 2012.

VILA, Marisa Iglesias. Las fuentes de indeterminación del derecho: uma aproximación filosófica. Revista Jurídica da UFERSA (REJUR), Mossoró, v. 2, n. 3, p. 22-47, jan./jun. 2018.

VILANOVA, Lourival. As estruturas lógicas e o sistema do direito positivo. São Paulo: Max Limonad, 1997. 